\title{
EVALUATION OF THE DAILY IRON INTAKE BY NON-BREASTFED EGYPTIAN INFANTS AND YOUNG CHILDREN
}

\section{El-Arab AM ${ }^{1 *}$, Mohammad $\mathbf{M}^{2}$ and M El-Sayed ${ }^{3}$}

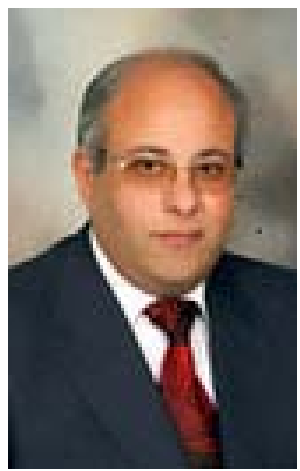

El-Arab Aly

*Corresponding author email: Alyabouelhassan@yahoo.com

${ }^{1}$ Associated Professor Doctor, Food Science and Nutrition Department, National Research Center, P.O. Box 12311, Tahrir St., Dokki, Giza, Egypt. Email: Alyabouelhassan@yahoo.com

${ }^{2}$ Researcher, Food Science and Nutrition Department, National Research Center, P.O. Box 12311, Tahrir St., Dokki, Giza, Egypt. Email: ama1mahmoud@yahoo.com

${ }^{3}$ Professor Doctor, Dairy Science Department, National Research Center, P.O. Box 12311, Tahrir St., Dokki, Giza, Egypt. Email: magdy_el_sayed@yahoo.com 


\section{ABSTRACT}

Iron deficiency is frequently associated with anaemia. The prevalence of anaemia among Egyptian infants and young children is $25 \%$. Fortification of infant and followup milk-based formulae remains a valuable method for delivering iron to reduce the incidence of iron deficiency anaemia. Percentage of Egyptian non-breastfed children consuming milk or milk products (7-23 months) are 79.1\%. No studies have focused on infant and follow-up milk-based formulae that are marketed in Egypt regarding iron fortification and consumption. The objective of the current study was to evaluate the intake of iron by non-breastfed Egyptian infants and young children. To achieve this goal the infant and follow-up milk based formulae brands and types, low - iron and iron - fortified, that are commercially available on the local market were collected. In addition, the iron concentration was determined in the collected formulae in relation to the label statements to ensure the correct intake. Finally, the actual daily intake of iron from formulae consumption was estimated in relation to the nutritional requirements. The CRM 1846 and 3126a were used for the precision and accuracy of the method. It was shown that the iron levels in all milk-based formulae were lower than those reported on the labels and ranged between $6.17-10.98 \mathrm{mg} / \mathrm{L}$. No significant difference was found between the average concentration of iron in lowiron formula brands $(8.1 \pm 2.3 \mathrm{mg} / \mathrm{L})$ and iron-fortified formula brands $(8.6 \pm 2.0$ $\mathrm{mg} / \mathrm{L})$. The average levels of the iron in the infant formula brands were lower $(\mathrm{p}<0.05)$ than follow-up formula brands. Iron- fortified infant brand $(0-6$ months $)$ met the DRI for iron. However, low-iron brands had iron intake of 5.5, 5.3, $4.7 \mathrm{mg} / \mathrm{day}$ in the $4^{\text {th }}$ month, $5^{\text {th }}$ month, and $6^{\text {th }}$ month, respectively, and were below the DRI. The Milk-based formula provided Egyptian infants (7-12 months) with only 30\% and young children (12-23 months) with $40 \%$ from their daily iron requirement. Although the purpose of iron fortification was to assist infants and young children in increasing their iron intakes to help reduce iron-deficiency anaemia, the current level of fortification will not ensure that all infants and young children achieve recommended intakes of iron.

Key words: Milk, Formula, Anemia, Iron-Fortification, Egypt 


\section{INTRODUCTION}

Breastfeeding is accepted as the best way to nurture a healthy infant of a healthy mother. The United Nations Children's Fund (UNICEF), World Health Organization (WHO) and multiple health organizations recommend exclusive breastfeeding with no other liquids (including water) or food for the first 6 months of Childs' life. Despite these recommendations, the vast majority of infants worldwide are fed infant formulae at some point in their first 6 months or year of life, whether as their sole source of nutrition or in combination with human milk, supplemental foods, or both [1]

Codex standard for infant formulae and for follow-up formulae stated that the term infant means a person not more than 12 months of age and the term young children means persons from the age of more than 12 months up to the age of three years. Codex standard for infant formula, applies to infant formula in liquid or powdered form intended for use, where necessary, as a substitute for human milk in meeting the normal nutritional requirements of infants. Follow-up formula means a food intended for use as a liquid part of the weaning diet for the infant from the $6^{\text {th }}$ month on and for young children $[2,3]$.

Iron $(\mathrm{Fe})$ is an essential trace element with a high prevalence of deficiency in infants and young children from developing countries. Iron deficiency is frequently associated with anaemia [4]. The anaemia prevalence in Egypt for infant and young children (6-59 months) is $25 \%$ [5]. Fortification of infant and follow-up milk-based formulae remains a valuable method for delivering iron to infant and young children that use a significant proportion to reduce the incidence of iron deficiency anaemia [6]. Evidence from observational studies suggests that children with iron deficiency anaemia suffer developmental disorders $[7,8]$.

In Europe, term infant formulae contain approximately $5-8 \mathrm{mg} / \mathrm{L}$ iron while in most other locations (including the United States) the iron content is approximately 12 $\mathrm{mg} / \mathrm{L}$ [9]. The previous Commission of the European Communities specified a minimum iron level of $0.5 \mathrm{mg} / 100 \mathrm{kcal}$ and a maximum iron level of $1.5 \mathrm{mg} / 100 \mathrm{kcal}$, a value which was modified recently to limits of $0.3 \mathrm{mg} / 100 \mathrm{kcal}$ and $1.3 \mathrm{mg} / 100 \mathrm{kcal}$ for the starting infant milk formula, respectively [10, 11]. Infant formulae have therefore been classified as low-iron or iron-fortified. Some commercially produced "iron-fortified" formulae contain approximately $12 \mathrm{mg} / \mathrm{L}$ of iron $(1.8 \mathrm{mg} / 100 \mathrm{kcal})$. Formula products labeled as "low-iron" contain iron between 1.3 and $4.7 \mathrm{mg} / \mathrm{L}(0.2$ and $0.7 \mathrm{mg} / 100 \mathrm{kcal})$. The justification for low-iron products is that, their use will alleviate gastrointestinal problems (mainly constipation), presumed to be associated with the elevated iron content of conventional formulae [12].

Percentage of Egyptian children under 6 months living with their mother who are exclusively breastfed are only $30.4 \%$ and the non-breastfed children consuming milk or milk products (7-23 months) are $79.1 \%$ [12, 13]. In addition, no studies have focused on infant and follow-up milk-based formulae that are marketed in Egypt

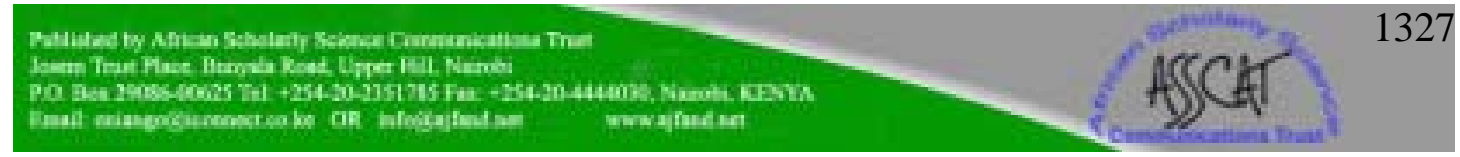


regarding iron fortification and consumption. The objective of this research was to evaluate the intake of iron by non-breastfed Egyptian infants and young children. To achieve this goal the infant and follow-up milk based formulae brands and types, low - iron or iron - fortified, that are commercially available on the local market were collected. In addition, the iron concentration was determined in the collected formulae in relation to the label statements and compared the iron content in formula brands and types to check the real content of iron and to ensure the correct intake. Finally, the actual daily intake of iron from infant and follow-up milk based formulae consumption was estimated in relation to the nutritional requirements.

\section{MATERIALS AND METHODS}

\section{Reagents}

Nitric acid and Hydrogen peroxide were obtained from Aldrich (Cat. No. 438073, 516813, respectively). LPDE sample bottles were from Fisher Scientific (Suwanee, GA, USA). Certified Reference Material (CRM 3126a), Iron Standard Solution was purchased from the National Institute of Standards and Technology (NIST), Gaithersburg, MD, USA. The calibration standard solutions used were made by appropriate dilution of the stock standards (by volume). Pure Deionized water with quality $0,1-20 \mu \mathrm{S} / \mathrm{cm}$ was prepared by feeding a TKA-DI, Ion Exchange Cartridges, Mixed bed systems (TKA Water purification systems GmbH, Stockland, Germany) with redistilled water [14].

\section{Sample digestion and flame atomic absorption spectrophotometer analysis of samples}

Sample digestion by Ethos Plus microwave labstation with computer-controlled easywave software (Milestone, CT, USA), was described elsewhere [14]. The labstation provides $100 \%$ reliable quality assurance of the analytical sample process through its quality pressure chemical sensor, vent and reseal vessel technology. Between 0.2 and $0.5 \mathrm{~g}$ of the infant and follow-up formulae powder samples were digested on the Ethos Plus microwave workstation. The conditions for the digestions are presented in Table 1. Duplicate digestions were conducted for each sample.

A Perkin-Elmer (Analyst 100- Perkin-Elmer Inc., USA) atomic absorption spectrophotometer (AAS) was used to measure the iron concentration in digested samples according to the conditions presented in Table 2 [15].

\section{Quality control}

Washing procedures for sample containers, the microwave digestion vessels, glassware for standards and AAS sample run tubes for iron metal determinations followed the standard procedures. In brief, sample containers and other glassware were cleaned with metal-free nonionic detergent solution, rinsed several times with distilled water, soaked in $50 \%$ nitric acid for $24 \mathrm{~h}$ and then rinsed many times with metal-free deionized water. All sample containers were rinsed again with deionized water prior to use [16]. 
For the precision and accuracy of the method, the CRM 1846 was analyzed. CRM 1846 was obtained from the National Institute of Standards and Technology (NIST), (Gaithersburg, MD, USA). Blanks, consisting of deionized water and reagents, as well as the CRM 1846 were subjected to similar sample preparation and analytical procedure.

\section{Sample collection}

Nineteen brands of dry powdered infant and follow-up milk-based formulae were purchased at commercial settings from pharmacies in Cairo, Giza, $6^{\text {th }}$ October and Kaluobia governorates. These four governorates represent $26.51 \%$ of the total Egyptian population [17]. The selection of these 19 brands of formulae were based mainly on food-frequency consumption pattern by the Egyptian infant and young children since they cover more than $91.35 \%$ of the total consumption [18]. Samples were purchased at various times (between April and November 2006) and from different pharmacies in these four governorates to guarantee good representation and allow for randomization. Table 3 presents the number and characteristics of infant and follow-up milk-based formulae used in this study.

\section{Daily intake of iron}

Estimates of the daily iron intake of Egyptian infant and follow-up formulae (0-6, 712, 13-23 months) were calculated using the feeding tables specified by the manufacturers of the various brands (boiled water, scoopfuls of powder formula and number of feeds per 24h). In fact the actual amounts consumed by Egyptian infants data are scarce, therefore additional studies are needed to establish the actual amount consumed by Egyptian infants.

\section{Statistical analysis}

Descriptive statistics that include means and standard deviation (SD) of the data were computed using Excel 2000. Milk-based formulations were compared through paired $\mathrm{t}$-test analysis at 5\% level of significance. In addition, the concentrations of $\mathrm{Fe}$ determined in the infant and follow-up formula samples, were subjected to one-way parametric ANOVA (analysis of variance) to ascertain at 95\% confidence level the homogeneity of variances across the brands.

\section{RESULTS}

\section{Certified reference material analysis}

The observed values of CRM 1846 analyzed using the same procedure were in agreement with the NIST certified values since the mean iron content in the CRM 1846 yielded a value of $10.28 \pm 0.02 \mathrm{mg} / \mathrm{g}$ (mean $\pm \mathrm{SD}$ of five determinations; certified value $10.00 \pm 0.02 \mathrm{mg} / \mathrm{g}$ ).

\section{Comparison between iron concentration and label information}

The iron concentration in infant formula, 0-6 months (brands 1-6 and 7-9) were 6.17 and $7.13 \mathrm{mg} / \mathrm{L}$, representing an adequacy of 9.62 and $6.48 \%$, with respect to label information which specified a content of 6.97 and $7.67 \mathrm{mg} / \mathrm{L}$, respectively (Table 4).

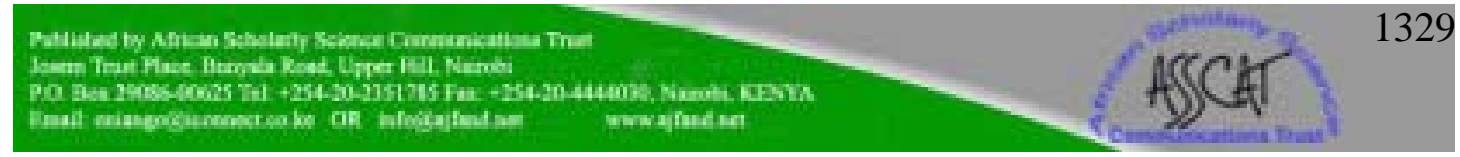


The iron levels in follow-up milk-formula, 7-12 months (brands 10-13 and 14, 15) were 10.48 and $8.39 \mathrm{mg} / \mathrm{L}$, which represents an adequacy of 10.78 and $11.97 \%$, with respect to label information which specified a content of 12.00 and $11.50 \mathrm{mg} / \mathrm{L}$, respectively. In addition, the iron levels in follow-up milk-formula, 13-23 months (brands 16, 17 and 18, 19) were 9.29 and $10.98 \mathrm{mg} / \mathrm{L}$, which represents an adequacy 10.80 and $10.56 \%$, with respect to label information which specified a content of 10.50 and $12.00 \mathrm{mg} / \mathrm{L}$, respectively.

\section{Iron concentration in milk-based formulae}

The average concentration of iron in low-iron infant formula (0-6 months, brands 1$6)$, were lower than the average values obtained for the iron-fortified (0-6 months, brands 7-9). However, the average iron concentration in low-iron follow-up milkformula (7-12 months, brands 10-13) were similar to the average value obtained from the iron-fortified (7-12 months, brands 14 and 15) (Table 4). In addition, iron concentration in low-iron follow-up milk-formulae for 13-23 months (brands 16 and 17) posted an average value lower than the value obtained for iron-fortified follow-up milk-formula for 13-23 months (brands 18 and 19). In general, iron in follow-up milkformula, 7-23 months (brands 10-13, 14 and 15) posted average values slightly higher but insignificant than the values obtained for follow-up milk-formula, 7-23 months $(14,15,18$ and 19). Brands 18, 19 had the highest iron value of $10.98 \mathrm{mg} / \mathrm{L}(1.39 \mathrm{mg} /$ $100 \mathrm{Kcal}$ ) while brands 14,15 (iron-fortified) had the lowest iron value of $8.39 \mathrm{mg} / \mathrm{L}$ (1.27 mg/ $100 \mathrm{Kcal})$ (Table 4).

\section{Comparison of milk-based formula brands}

The average concentration of iron in infant formulae 0-6 months (brands 1-6 and 7-9) were lower than both of the average values obtained for the follow-up milk formulae 7-12 months (brands 10-13 and 14 \&15) and follow-up milk formulae 13-23 months (brands 16, 17, 18 and 19). The follow-up formulae (7-12 months, brands 10-13, 14 and 15) had higher average concentration of the iron than the average of the values obtained for infant formula (0-6 months, brand 1-6, 7-9) and follow-up formulae (1323 months, brands 16, 17, 18 and 19) (Table 4).

\section{Daily intake}

The estimated daily intake of iron from Egyptian infant formulae in the $4^{\text {th }}, 5^{\text {th }}, 6^{\text {th }}$ months of age were 5.5, 5.3, $4.7 \mathrm{mg} /$ day, respectively for low-iron brands. In contrast, the intakes were 6.4, 6.6, 6.1 mg/day, respectively for iron-fortified brands (Table 5).

For infants and young children (7-23 months), the calculated daily intakes of iron from different formula brands were compared with Recommended Dietary Allowances (RDA) and Dietary Reference Intakes (DRI) for use in North America, World Health Organization (WHO) and United Nations Food and Agriculture Organization / World Health Organization (FAO/WHO) and The European Union (EU) (Table 6) $[19,20,21]$. The estimated daily intake of iron from infant (7-12 months, brands 10-13 and brands 13 and 14) and follow-up formulae (13-23 months, brands 16, 17, 19 and 19) were below the RDA and DRI for use in North America, WHO and FAO/WHO and EU (Table 7). Daily intake of iron was highest in Low-iron

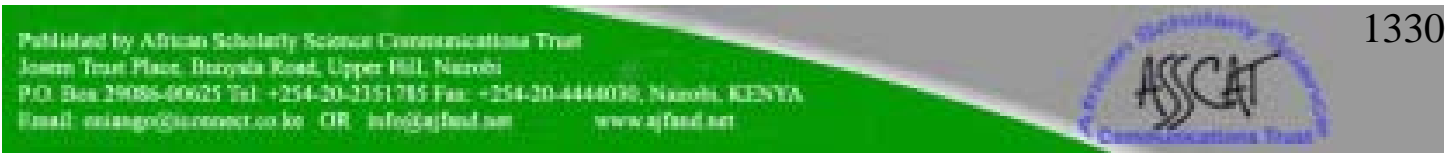


follow-up milk formula brands (7-12 months, $5.77 \mathrm{mg} /$ day) and lowest in low-iron follow-up milk formula brands (13-23 months, $3.9 \mathrm{mg} /$ day).

\section{DISCUSSION}

The European Communities Commission [11] established the limits of nutrients, which can be added to meet nutritional requirements and to guarantee the stability of the product. It is usual for manufacturers to add a higher quantity of nutrients to the formulas than that indicated on the formulas label, to compensate for losses during manufacture and storage. However, the real content of those nutrients after manufacture and storage needs to be checked, to ensure correct intake and the accuracy of the label statements.

In all the milk-based formulae in this study, the values of iron were lower than the values reported on the labels (with exception for only brand 2 and brand 7). It is assumed that this may be due to variation in the materials that were used to prepare the infant and follow-up milk-based formulae. It is necessary to ensure that ironfortification meet the content stated on the labels. On contrast, the paired t-test, at 5\% level of significance, between the milk-based formulae in Egypt (label information versus analyzed) indicate no significant variation of the concentrations of iron (Table 4). Generally, the iron levels in all milk-based formulae were found between 6.17 and $10.98 \mathrm{mg} / \mathrm{L}$, representing adequacy values from 9.62 to $10.56 \%$, with respect to label information. The adequacy values for the infant and follow-up formula analysed in this study did not show such large adequacy values reported by others, who found that the values of iron in milk-based formula were between 3.98 and $4.59 \mathrm{mg} / 100 \mathrm{~g}$, representing adequacy values from $65.3 \%$ to $75.3 \%$, with respect to label information [22].

The mean level of iron in low-iron formulae (all low-iron brands, $8.1 \pm 2.3 \mathrm{mg} / \mathrm{L}$ ), were generally similar to the combined average iron levels in the iron-fortified formula (all iron-fortified brands, $8.6 \pm 2.0 \mathrm{mg} / \mathrm{L}$ ), with no significant differences. In addition, iron-fortified follow-up formula brands (7-23 months) had iron value $(9.96 \mathrm{mg} / \mathrm{L})$ less than low-iron follow-up formula brands $(10.08 \mathrm{mg} / \mathrm{L}$, not significant). Therefore, the measured values of the Egyptian low-iron or iron-fortified milk-based formulae is not in conformity with the American Academy of Pediatrics classification (i.e. low-iron and iron-fortified contain less than and more than $6.7 \mathrm{mg} / \mathrm{L}$, respectively) [23].

There is no minimum level established for the iron in the infant formula in Egyptian standards [24]. In brands 1-6 the iron contents were below $6.7 \mathrm{mg} / \mathrm{L}(1 \mathrm{mg} / 100 \mathrm{Kcal})$, stipulated CODEX STAN 72-1981 for infant formula [2]. In contrast, brands 7-9 were above $6.7 \mathrm{mg} / \mathrm{L}(1 \mathrm{mg} / 100 \mathrm{Kcal})$, stipulated CODEX STAN 72-1981 for infant formula (Table 4) [2]. Accordingly, these values disagree with the Committee on Nutrition, American Academy of Pediatrics recommendations since formula-fed infants should consume iron-fortified infant formulae until 12 months of age to reduce the risk of iron deficiency [9]. On the other hand, none of the iron values for follow-

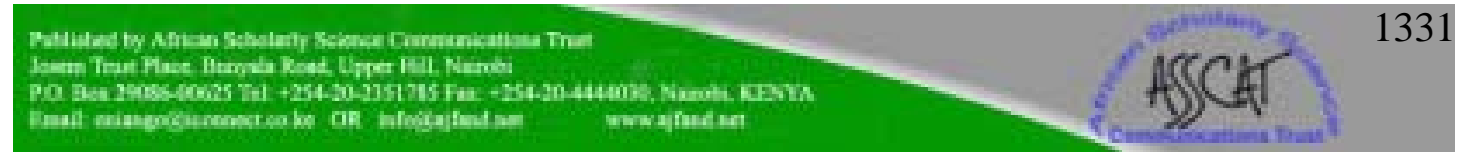


up formulae (7-23 months.) were below $6.7 \mathrm{mg} / \mathrm{L}(1 \mathrm{mg} / 100 \mathrm{Kcal})$, or exceeded the 13 $\mathrm{mg} / \mathrm{L}(2 \mathrm{mg} / 100 \mathrm{Kcal})$ stipulated CODEX STAN 156-1987 [3].

The mean level of the iron in the infant formulae (brands 1-6 and 7-9) were significantly $(\mathrm{p}<0.05)$ lower than the corresponding combined values obtained from the follow-up formula (7-12 months and 13-23 months). This differs with other studies that focused on follow-up formulae marketed in Europe indicating higher iron values for infant formulae $(12 \mathrm{mg} / \mathrm{L}$ ) in comparison to follow-up formula (e. g, 6.5 $\mathrm{mg} / \mathrm{L}$ ) [25]. T-test, at 5\% level of significance revealed significant difference between all infant formula types (brands 1-6, 7-9) versus follow-formula types (brands 10-13, $14,15,16,17,18$ and 19 in the concentrations of iron. The result of the one-way parametric ANOVA across all infant and all follow-up formula brands that were in iron-fortified also suggests significant differences at the $95 \%$ confidence level in the variances of iron. Similarly, ANOVA result of the Low-iron formula brands suggests unequal variances of iron at the 5\% level of significance. This indicates that various formulae brands may have different iron values and may, as well, cause potentially different levels of iron consumption( Table 5,7).

According to the Institute of Medicine (IOM) the DRI of iron met by exclusive breast feeding is $0.27 \mathrm{mg} / \mathrm{d}(0.78 \mathrm{~L}$ milk/d, $0.35 \mathrm{mg} \mathrm{Fe} / \mathrm{L})$ [ 26 ]. By definition, this approach derives an "adequate intake" rather than a RDA. FAO/WHO and the EU provide no recommendation for this very young age bracket $[19,20]$. Therefore, the calculated daily intake of iron from each Egyptian infant formula brands were compared with RDA and DRI for use in North America for non breastfed infants. The RDA or DRI for 0-6-months-old non breastfed infants is $6 \mathrm{mg} \mathrm{Fe/day} \mathrm{[21].}$

According to the Egyptian first milk-based formulae, for normal healthy infants and $4^{\text {th }}, 5^{\text {th }}, 6^{\text {th }}$ months of age, the specified feed intake per day ranged from 630 to 1050 $\mathrm{ml}$ for brands 1-6 and 7-9. Only brands 7-9 met the DRI for iron. However, brands 16 had iron intake $\left(5.5,5.3,4.69 \mathrm{mg} /\right.$ day in the $4^{\text {th }}, 5^{\text {th }}, 6^{\text {th }}$ months, respectively) below the RDI. In conclusion, not all Egyptian infant formula (0-6 months) brands in this study met the DRI for iron. In addition, percentage of Egyptian children who are exclusively breastfed ( $<6$ months) declined from $53 \%$ to only $30 \%$ [12, 13, 27]. Non breastfed infants consuming formulations (sole source of nutrition) with low levels of iron may suffer nutritional deficiencies and consequent health problems [26]. Therefore, efforts are warranted to promote, support, and protect breastfeeding in Egypt and elsewhere. In light of the data presented above, the milk-based formulae for non-breastfed infants (0-6 months) should be fortified at level not less than $6.73 \mathrm{mg} / 1$ to achieve $6 \mathrm{mg}$ Fe/day. The fortification level $(6.73 \mathrm{mg} / \mathrm{L})$ should be considered, especially in countries that suffer from anaemia (e. g. Egypt) as recommended by the American Academy of Pediatrics [9]. In addition the following two important recommendations are suggested. First, the Egyptian manufacturer of formulae with iron concentrations less than $6.7 \mathrm{mg} / \mathrm{L}$ should be labeled as "potentially nutritionally inadequate" with a warning specifying the risk of iron deficiency, or their manufacture should be discontinued. Second, the Egyptian standards of infant feeding milk-based formulae should be modified and established especially for Egyptian

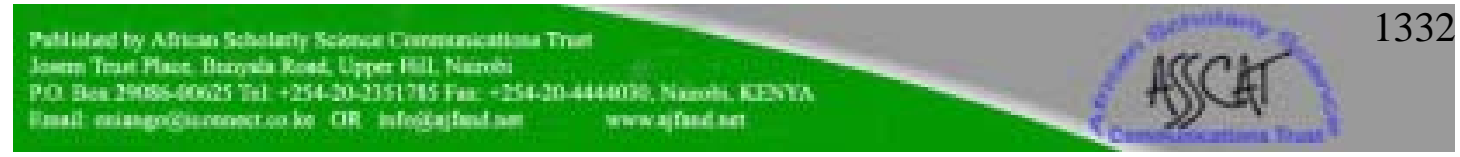


conditions and should not include iron content not less than $6.73 \mathrm{mg} / \mathrm{L}$ (to achieve 6 $\mathrm{mg} \mathrm{Fe} /$ day) and not more than $13 \mathrm{mg} / \mathrm{L}$ [24]. In contrast, some or all of the infants within each group may benefit from receiving additional iron, while some may be harm (experience constipation) [28]. However, we believe that the population that benefit from iron fortification will be larger than the population that experiences harmful effects.

All of the Egyptian infant and follow-up formula (7-12 and 13-23 months) brands in this study do not meet the WHO, IOM, DRI, FAO/WHO and EU recommended iron supplementation levels. The Egyptian infant and follow-up formulae developed for children aged 7-23 months is likely to be inadequate to meet the iron requirements as found also by Lutter and Dewey [ 29 ]. This means that the infant (7-12 months) and young children (13-23 months) should get their iron requirement from complementary foods.

In addition and specifically, the differences between the recommendations of the RDA, WHO, IOM, DRI, FAO/WHO and EU may provide a clue to spot assessment problems (Table 6). For example, the RDAs were explicitly developed for the US population with a solid database for the average weight and dietary fare. However, if RDAs are used to estimate iron requirements in Third World populations, obvious differences from the US settings will be needed. Most critical in this respect is the fractional absorption of $18 \%$ that assumes a diet with high iron bioavailability. If we assume a typical Third World diet, which is based almost exclusively on vegetarian food staples such as rice or corn, iron bioavailability will rather be as low as 5\% [30]. FAO/WHO took care of this problem by adapting their recommendations to differences in bioavailability from the respective diets in different countries. Therefore, the calculated daily intake of iron from all Egyptian infant and young children formula brands were compared with FAO/WHO (18.6 and $11.6 \mathrm{mg} / \mathrm{d}$ for 612 and 13-23 months, respectively), Assuming medium bioavailability 5\%. The estimated daily intake of iron from all studied Egyptian infant (7-12 months, brands 10-13 and brands 13 and 14) and follow-up formula (13-23 months, brands 16, 17, 19 and 19) were dramatically below the FAO/WHO level. In contrast, the infants (7-12 months) and young children (13-23 months) milk-based formula provide infants and young children $31.02,30.06,33.62$ and $39.74 \%$ for brands $10-13$, brands 14,15 , brands 16,17 and brands 18,19, respectively of their daily iron requirement.

In addition, Egyptian Non-breastfed children who had consumed food rich in iron (Includes meat, organ meat, fish, poultry, and eggs) in the previous 24 hours were $61.9 \%$ [12]. Therefore, around $38.1 \%$ of Egyptian infant and young children might suffer from iron deficiency. Such infants and young children (7-23 months) should receive the rest of iron from the complementary or house food rich in iron to meet their iron requirement (around 60-70\%). In addition, interventions to improve and promote the nutritional formulations of iron-fortified complementary foods are essential in Egypt. Furthermore, it is difficult to ensure that the rest of iron requirement can be obtained from the complementary food or house food rich in iron where there are no data available to apply this approach. Data are also limited on a

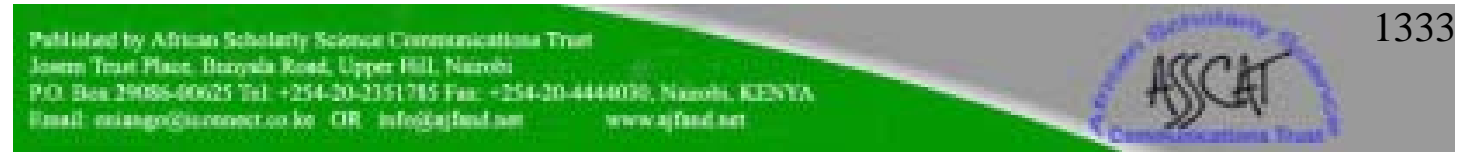


number of the factors considered herein, such as the appropriate daily ration size, contribution of human milk to meet iron requirements, contribution of infant and young children formulae and bioavailability of iron. Harmonization of iron requirements for infants and young children (7-23 months) is also needed to ensure a more standardized approach.

Because all of the previous limitations, the gap between iron-fortified formulae and complications of iron deficiency (prevalence of anaemia) still present and represent a national threat. Therefore, iron supplementation should be given to the infants (7-12 months) and young children (13-23 months) in the form of national project under the supervision of Ministry of Health. In addition, more parents and caregivers can benefit from guidance about the introduction of appropriate, iron-rich first complementary foods such as iron-rich infant cereals, iron-fortified grain products, meats, soft fruits, and cooked vegetables. The importance of breastfeeding through the first year of life is also noted. Finally, a strategy for improved infant and young child feeding is essential to capture the attention of policy makers and their limited human and financial resources.

\section{CONCLUSION}

Although the purpose of iron fortification is to assist infants and young children in increasing their iron intakes to help reduce iron-deficiency anaemia, the current level of fortification does not ensure that all infants and young children achieve recommended intakes of iron. In light of the results of this study, to enhance the iron intake and avoid iron-deficiency anaemia, it is recommended that: 1) Modification of the Egyptian standards for infant and young children milk-based formulae should be done to include iron content not less than $6.73 \mathrm{mg} / \mathrm{L} ., 2$ ) Ensure that iron-fortification meets the content stated on the labels. 3) Egyptian manufacturers of formulae with iron concentrations less than $6.7 \mathrm{mg} / \mathrm{L}$ should be labeled as "potentially nutritionally inadequate" with a warning specifying the risk of iron deficiency. 4) Iron supplementation should be given to the infants (7-12 months) and young children (1323 months). 5) Finally, there should be an improved strategy for infant and young child feeding to capture the attention of policy makers and their financial resources.

\section{ACKNOWLEDGMENTS}

This study was supported by the National Research Center. We thank Bill Chasse, Food and Drug Administration (FDA), Atlanta, Georgia, USA for providing the CRM. 
Table 1 : Ethos Plus microwave labstation digestion conditions ${ }^{\text {a }}$

Sample, powder

Nitric acid

Hydrogen peroxide

Pressure

Power-Temperature ${ }^{\mathrm{b}}$

Stirring (200 RPM)
$0.2-0.5 \mathrm{~g}$

$4 \mathrm{ml}$

$2 \mathrm{ml}$

$1500 \mathrm{psi}$

Step 1: $2 \mathrm{~min}$ at $250 \mathrm{~W}^{\mathrm{c}}$;

Step 2: $1 \mathrm{~min}$ at $0 \mathrm{~W}$;

Step 3: $5 \mathrm{~min}$ at $250 \mathrm{~W}$,

Step 4: $5 \mathrm{~min}$ at $400 \mathrm{~W}$,

Step 5: $5 \mathrm{~min}$ at $650 \mathrm{~W}$,

Step 6: $10 \mathrm{~min}$ at $0 \mathrm{~W}$ (vent), and cool to room temperature Stirring prevented formation of clumps

${ }^{a}$ Digestion procedures were adapted from the Milestone Ethos-PLUS microwave labstation user manual. The Ethos-PLUS is equipped with a high pressure segmented rotor, internal temperature and pressure monitoring system.

b Temperature ramping was used to control the exothermic reaction and over pressurization of digestion vessel.

c The Milestone microwave easywave software automatically delivers the required temperature profile to follow the power, according to the Ethos-PLUS microwave labstation user manual 
Table 2: Instrument operating conditions applied for iron determination by atomic absorption spectrophotometer

Wave length (nm)

248.3

Slit width

0.2

Flame type

Air $/ \mathrm{C}_{2} \mathrm{H}_{2}$

Flow rates of Air/acetylene (1/min)

$9 / 3$

Lamp

Hollow cathode

Lamp current

30 
Table 3: Characteristics and classification of infant and follow-up milk-based formulae under study
Age group ${ }^{\mathrm{a}},{ }^{\mathrm{b}}$
Brand code ${ }^{\mathrm{c}}$
Formula information $^{c}$
Infant formula, 0-6 months or from birth
$1-6(n=12)$
Low-iron
$7-9(n=4)$
Iron-fortified $^{\mathrm{d}}$
Follow-up milk formula, 7-12 months
$10-13(n=6)$
Low-iron
$14,15(n=4)$
Iron-fortified $^{\mathrm{d}}$
Follow-up milk formula, 13-23 months
$16,17(\mathrm{n}=5)$
Low-iron
$18,19(\mathrm{n}=5)$
Iron-fortified $^{\mathrm{d}}$
${ }^{a}$ As described on the infant and follow-up formula labels.
${ }^{\mathrm{b}}$ All samples were in powder form and in metal container.
${ }^{\mathrm{c}} \mathrm{n}=$ number of samples per brand.
${ }^{\mathrm{d}}$ Fortification with iron sulphate 
Table 4: Analysis of iron content in infant and follow-up milk-based formulae

\begin{tabular}{lclc} 
Sample descriptions $^{1}$ & $\begin{array}{c}\text { Fe label }^{1} \\
(\mathrm{mg} / \mathrm{L})\end{array}$ & $\begin{array}{l}\text { Fe analyzed } \\
(\mathrm{mg} / \mathrm{L})\end{array}$ & $\begin{array}{c}\text { Adequacy }^{2} \\
(\%)\end{array}$ \\
\hline
\end{tabular}

Infant formulae, 0-6 months

$\begin{array}{llll}\text { Low-iron } & 6.97 \pm 1.42 & 6.17 \pm 0.91 & 9.62 \pm 13.35 \\ \text { Iron-fortified } & 7.67 \pm 0.68 & 7.13 \pm 0.36 & 6.48 \pm 11.34 \\ \text { Total } & 7.20 \pm 1.21^{\mathrm{b}} & 6.49 \pm 0.89 & 8.57 \pm 12.08\end{array}$

Follow-up formulae, 7-12 months

$\begin{array}{lccc}\text { Low-iron } & 12.00 \pm 0.00 & 10.48 \pm 0.31 & 10.78 \pm 3.18 \\ \text { Iron-fortified } & 11.50 \pm 0.71 & 8.39 \pm 2.16 & 11.96 \pm 2.94 \\ \text { Total } & 11.83 \pm 0.41^{\mathrm{b}} & 9.78 \pm 1.47 & 11.17 \pm 2.86\end{array}$

Follow-up formulae, 13-23 months

$\begin{array}{lccc}\text { Low-iron } & 10.50 \pm 0.54^{\mathrm{a}} & 9.29 \pm 2.89^{\mathrm{a}} & 10.80 \pm 1.80 \\ \text { Iron-fortified } & 12.00 \pm 0.00 & 10.98 \pm 0.06 & 10.56 \pm 1.00 \\ \text { Total } & 11.35 \pm 2.22^{\mathrm{b}} & 10.14 \pm 1.94 & 10.68 \pm 1.20\end{array}$

Follow-up formulae, 7-23 months

$\begin{array}{lccc}\text { Low-iron } & 11.50 \pm 1.76 & 10.08 \pm 1.45 & 10.79 \pm 2.59 \\ \text { Iron-fortified } & 11.75 \pm 0.50 & 9.69 \pm 1.95 & 11.26 \pm 1.96 \\ \text { Total } & 11.60 \pm 1.35^{\mathrm{b}} & 9.92 \pm 1.58 & 10.98 \pm 2.26\end{array}$

Values are expressed as means \pm standard deviation.

${ }^{a}$ The same superscripted letters within the same raw or column indicate significant differences $(\mathrm{p}>0.05)$.

1 As declared on the label.

2 Adequacy $\%=(($ Fe label - Fe analyzed $) /$ Fe label $) * 100$. [ 22 ] 
Table 5: Average daily intake of iron for first term infant milk-based formulae in Egypt

Brands Daily intake, first term formula (Fe mg/day)

$4^{\text {th }}$ month $\quad 5^{\text {th }}$ month $\quad 6^{\text {th }}$ month

\begin{tabular}{llll} 
Brands 1-6 & 5.5 & 5.3 & 4.69 \\
Brands 7-9 & 6.42 & 6.63 & 6.11 \\
All brands & 5.84 & 5.78 & 5.16 \\
\hline
\end{tabular}


Table 6: Comparison of iron requirements of infants aged 7-12 and 13-23 months, WHO, IOM and DRI, and FAO/WHO and EU values *

7-12 months

13-23 months

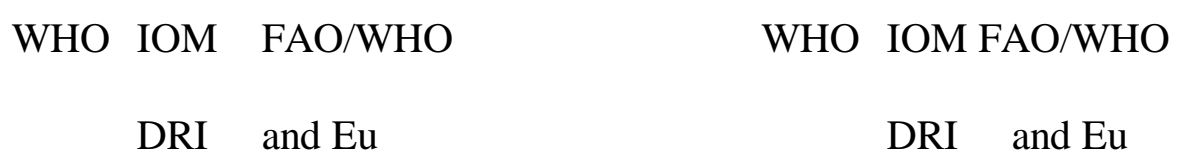

\begin{tabular}{|c|c|c|c|c|c|c|}
\hline $\mathrm{Fe} \mathrm{mg} / \mathrm{d}^{\mathrm{a}}$ & 11 & 11 & 9.3 & 6 & 7 & 5.8 \\
\hline $\mathrm{Fe} \mathrm{mg} / \mathrm{d}^{\mathrm{b}}$ & - & - & 18.6 & - & - & 11.6 \\
\hline
\end{tabular}

* Source: FAO/WHO [ 19 ], Scientific Committee on Food of the European

Commission [ 20 ], IOM [ 21 ] and Lutter and Dewey [ 29 ].

${ }^{a}$ Assuming medium bioavailability (10\%).

${ }^{\mathrm{b}}$ Assuming medium bioavailability (5\%).

DRI, Dietary Reference Intakes; IOM, Institute of Medicine 
Table 7: Average daily intake of iron for infant and follow-up milk-based formula in Egypt

Brands

Daily intake of iron (mg/day)

Brands 10-13

Brands 14, 15

Brands 10-13, 14, 15

Brands 16, 17

Brands 18, 19

Brands 16, 17, 18, 19

Brands 10-13, 16, 17

Brands 14, 15, 18, 19

All brands
$5.77 \pm 2.65$

$5.59 \pm 0.92$

$4.91 \pm 0.78$

$3.90 \pm 1.22$

$4.61 \pm 0.02$

$4.26 \pm 0.81$

$5.15 \pm 2.33$

$5.10 \pm 0.78$

$5.13 \pm 1.80$ 


\section{REFERENCES}

1. IOM. Institute of Medicine, Infant Formula: Evaluating the Safety of New Ingredients. National Academy Press, Washington DC. 2004.

2. FAO/WHO. United Nations Food and Agriculture Organization / World Health Organization, Codex Standard for Infant Formula, CODEX STAN 72-1981 (amended 1983, 1985, 1987, 1997). WHO, Geneva, Switzerland, 1997.

3. FAO/WHO. United Nations Food and Agriculture Organization / World Health Organization, Codex Standard Follow-up Formula, CODEX STAN 156-1987 (amended 1989). WHO, Geneva, Switzerland, 1989.

4. Schumann K, Ettle T, Szegner B, Elsenhans B and N Solomons On risks and benefits of iron supplementation recommendations for iron intake revisited. J. Trace. Elem. Med. Bio. 2007; 21: 147-168.

5. Al-Buhairan AM and OA Oluboyede Determination of serum iron, total ironbinding capacity and serum ferritin in Saudi adults. Annals. of Saudi medicine. 2001; 21(1-2): 100-106.

6. Ramakrishnan $\mathbf{U}$ Functional consequences of nutritional anemia during pregnancy and early childhood. In U Ramakrishnan (Ed.). Nutritional Anemia's. Boca Raton FL., CRC Press 2001. pp 43-68.

7. Lozoff B Perinatal iron deficiency and the developing brain. Pediatr. Res. 2000; 48: $137-139$.

8. Lozoff B, Jimenez E, Hagen J, Mollen E and AW Wolf Poorer behavioral and developmental outcome more than 10 years after treatment for iron deficiency in infancy. Pediatrics 2000, 105: E51.

9. American Academy of Pediatrics The use of whole cow's milk in infancy. Pediatrics 1992; 89: 1105-1109.

10. 96/4/CE: Directiva 96/4/CE de la Comisión, de 16 de febrero de 1996, por la que se modifica la directiva 91/321/CEE relativa a los preparados para lactantes y preparados de continuación. DOUE n. 49 de 28/02/1996, 1996. pp 12-16.

11. 2006/141/CE: Directiva 2006/141/CE de la Comisión de 22 de diciembre de 2006 relativa a los preparados para lactantes y preparados de continuación y por la que se modifica la Directiva 1999/21/CE.L 401, 2006. pp 1-33.

12. Mukuria A, Kothari $\mathbf{M}$ and $\mathbf{N}$ Abderrahim Infant and Young Child Feeding Update. ORC Macro, Calverton, Maryland, USA. 2006. 
13. UNICEF. United Nations Children's Fund, The state of the world's children. UNICEF - NY 10017. New York. 2006.

14. Cubadda F, Raggi A, Testoni A, and F Zanasi Multielemental analysis of food and agricultural matrixes by inductively coupled plasma-mass spectrometry. J. AOAC Inter. 2002; 85: 113-121.

15. AOAC. Association of Official Analytical Chemists. Official methods of analysis of the Association of Official Analytical Chemists (15th Ed.). Washington DC, 1990.

16. American Public Health Association: Standard methods for the examination of water and wastewater $\left(20^{\text {th }}\right.$ Ed.). American Water Works Association and Water Environment Federation, New York, 1998.

17. Central Agency for Public Mobilization and Statistics (CAPMAS), Egypt: The final results of Census, http://www.capmas.gov.eg/.2006.

18. Henein W and U Tharwat Master on therapeutic drugs. MTD, Egypt, 2007.

19. FAO/WHO. United Nations Food and Agriculture Organization / World Health Organization, Requirements of vitamin A, iron, folate, and vitamin B12. FAO Food and Nutrition Series, No 23. Rome. 2004. pp 246-278.

20. Scientific Committee on Food of the European Commission: Opinion on food, on nutrition and energy intakes for the European Community.http://ec.Europa.Eu/comm./food/fs/sc/scf/Out89.pdfS. 1989.

21. IOM. Institute of Medicine, Dietary reference intakes for calcium, phosphorus, magnesium, vitamin D, and fluoride. National Academy Press, Washington DC. 1997.

22. Chavez-Servin J, Castellote A, Rivero M and M Lopez-Sabater Analysis of vitamins $\mathrm{A}, \mathrm{E}$ and $\mathrm{C}$, iron and selenium contents in infant milk-based powdered formula during full shelf-life. Food Chem. 2008; 107: 1187-1197.

23. American Academy of Pediatrics Iron fortification of infant formulas. Pediatrics 1999; 104: 119-124.

24. EC 2072/1991: Egyptian standard: Infant formula. Egyptian Organization for Standardization and Quality, Egypt, 1991.

25. Singhal A, Morley R, Abbott R, Fairweather-Tait S, Stephenson T, Frcpchi F and A Lucas Clinical Safety of Iron-Fortified Formulas . Pediatrics 2000; 105: 3-6. 
26. IOM. Institute of Medicine, Dietary reference intakes for vitamin A, vitamin K, arsenic, boron, chromium, copper, iodide, iron, manganese, molybdenum, nickel, silicon, vanadium and zinc. National Academy Press, Washington DC. 2001.

27. UNICEF. United Nations Children's Fund, The state of the world's children. UNICEF - NY 10017. New York, 1998.

28. National Academy of Sciences New Findings on Poverty and Child Health and Nutrition. National Academy Press. Washington DC. 1998.

29 Lutter C and K Dewey Proposed Nutrient Composition for Fortified Complementary Foods. J. Nutr. 2003; 133: 3011S-3020S.

30. Monsen ER Iron nutrition and absorption: dietary factors which impact iron bioavailability. J. Am. Diet. Assoc. 1988; 88: 786-790. 